\title{
APLICABILIDAD DE LA TEORÍA DE LAS CARGAS PROBATORIAS DINÁMICAS AL PROCESO CIVIL PERUANO. APUNTES INICIALES
}

\author{
WALter EduARdo CAMpos Murillo*
}

\section{Resumen}

El presente artículo pretende aportar algunos apuntes iniciales a fin de establecer la conveniencia de aplicar la denominada "Teoría de las Cargas Probatorias Dinámicas" en el proceso civil peruano. Esta teoría que constituye un medio para flexibilizar, de manera excepcional, la rigidez de la regla general de distribución de la carga probatoria recogida en el artículo 196 del Código Procesal Civil, constituye un aporte de la doctrina procesal argentina a la teoría general de la prueba y que, pese a no estar regulada normativamente, ha sido acogida ya en diversos ámbitos de nuestro derecho nacional. En esta línea, luego de establecida la conveniencia de su adopción en sede nacional, se propone un texto normativo para su incorporación en el derecho procesal civil peruano.

Palabras clave: Prueba - Carga probatoria - Carga probatoria dinámica Teoría de la prueba.

\begin{abstract}
This article aims to provide some initial notes in order to establish the suitability of applying the so-called "theory of the evidentiary dynamic loads" in the Peruvian civil process. This theory which provides a means to make more flexible, by way of exception, the rigidity of the general rule of distribution of burden of proof contained in article 196 of the code of Civil procedure, constitutes a contribution of the Argentine procedural doctrine to the general theory of the test and that, despite not being regulated normatively, has been already received in various fields of our national law. In this line, then established the suitability of adoption at national headquarters, proposes a regulatory text for inclusion in the Peruvian civil procedural law.
\end{abstract}

Key words: Test - Burden of proof - Load dynamic probation - General theory of test.

\section{Sumario}

I. Introducción. II. La carga de la prueba. III. La teoría de las cargas probatorias dinámicas. 1. Concepto. 2. Caracteres. 3. Contenido. IV. Aplicación de la teoría de las cargas probatorias dinámicas en el ámbito nacional. 1) Ámbito Constitucional. 2) Ámbito de protección al consumidor. 3) Ámbito jurisdiccional. V. Propuesta normativa. VII. Reflexiones finales.

\footnotetext{
* Juez Titular del Juzgado Mixto del Módulo Básico de Justicia de Carabayllo, de la Corte Superior de Justicia de Lima Norte - Poder Judicial del Perú. Profesor de la Universidad Cesar Vallejo, sede Lima.
} 
Walter Eduardo Campos Murillo - Aplicabilidad de la teoría de las cargas probatorias dinámicas al Proceso Civil Peruano. Apuntes iniciales

\section{INTRODUCCIÓN}

Un repetido aforismo jurídico reza: "Tanto vale no tener un derecho como tenerlo y no poder probarlo"; ello evidencia la importancia trascendente que tiene la prueba en el ámbito del proceso, pues a través de los diversos medios de prueba, los hechos que configuran una pretensión o una defensa pueden dejar de ser simples afirmaciones para pasar a ser hechos sobre los cuales el Juez se forma convicción; sin ella, los hechos del caso y los petitorios de las partes no son más que simples conjeturas sin mayor eficacia jurídica. La prueba es la que permite al Juez conectar lógicamente el Derecho con la realidad del caso concreto.

Son dos los sistemas que regulan la prueba judicial ${ }^{1}$ : el sistema dispositivo y el inquisitivo; el primero supone, en esencia, que la actividad probatoria corresponde únicamente a las partes, mientras que en el segundo dicha actividad probatoria no es exclusiva de las partes sino que el Juez tiene un rol trascendente, pudiendo incluso ordenar la actuación de medios probatorios de oficio a fin de verificar lo afirmado por las partes dentro del proceso. Cada uno de estos sistemas se insertan a su vez en dos concepciones del proceso o sistemas procesales claramente definidos y diferenciables; así el sistema dispositivo es parte del sistema procesal privatístico, mientras que el sistema inquisitivo se instaura dentro de una concepción del proceso conocida como sistema procesal publicístico.

El sistema procesal privatísitico parte por considerar que si en el proceso civil se discuten derecho civiles que son privados, entonces el proceso civil es también una actividad privada, constituyéndose en el medio a través del cual el Estado concede a los particulares la oportunidad de resolver sus conflictos de intereses; por su parte, el sistema procesal publicístico considera que lo más importante no es que los particulares resuelvan sus conflictos sino que, a través de él, el derecho objetivo se torna eficaz y respetado, siendo además que a través de la exigencia judicial del cumplimiento del derecho objetivo, se lograra la paz social en justicia, de lo que sigue que el proceso es un fenómeno público, sujeto a normas de derecho público.

No obstante, pese a la notoria diferencia entre ambos sistemas, no existe país en el que alguno de estos sistemas se presente químicamente puro a nivel

\footnotetext{
1 Monroy Gálvez, Juan. «Los límites éticos de la actividad probatoria». En: La Formación del Proceso Civil Peruano. Lima: Communitas, 2010; p 577.
} 
Walter Eduardo Campos Murillo - Aplicabilidad de la teoría de las cargas probatorias dinámicas al Proceso Civil Peruano. Apuntes iniciales

normativo, sino lo que se evidencia es, en todo caso, la preponderancia de uno respecto de otro ${ }^{2}$.

Efectuada tal diferenciación de sistemas procesales, tenemos que la teoría de las cargas probatorias dinámicas (en adelante TCPD) se ubica en la concepción publicista del proceso, ahí donde prima el sistema inquisitivo, donde el papel del Juez es activo y goza de amplias facultades y poderes como director del proceso, para lograr la reconstrucción artificial de los hechos en el proceso y establecer quién tiene la razón llegando a la verdad real procesal.

La TCPD rompe la regla rígida que sostiene todo el aparato distributivo de la carga de la prueba en nuestro sistema procesal, regla según la cual "quien afirma, debe probar", proponiendo más bien que, de manera excepcional, en casos de prueba difícil o imposible, la carga de la prueba recae en el sujeto del proceso que se encuentra en mejores condiciones, en mayor aptitud para proporcionar el material probatorio vinculado a la materia controvertida, independientemente de si es el actor o el demandado que afirmó el hecho.

En este contexto es que en el presente artículo desarrollaremos la aplicabilidad de la TCPD en el proceso civil peruano, con tal finalidad partiremos de una aproximación a la idea de carga procesal para luego desarrollar el concepto, características y contenido de esta teoría, revisar su aplicación en sede nacional $\mathrm{y}$, finalmente, establecer la conveniencia de su aplicación en el proceso civil peruano a través de una regulación expresa que resulte específica.

\section{LA CARGA DE LA PRUEBA}

La carga de la prueba (o el onus probandi) es una especie del género carga procesal y puede ser entendida como una noción procesal compleja que consiste en una regla de juicio que contiene dos aspectos fundamentales, de un lado le indica al Juez como debe sentenciar cuando no aparezcan en el proceso pruebas que le den certeza sobre los hechos que deben sustentar su decisión y, de otro lado, a las partes la responsabilidad que tienen para que los hechos que sirven de sustento de sus posiciones aparezcan demostrados ${ }^{3}$.

\footnotetext{
MONROY GÁlveZ, Juan. Op cit., p. 578.

3 RosengerG, Leo. «La Carga de la prueba». Editorial IB de F. 2da. Edición. Traducción Ernesto Krotoschin. Montevideo-Bs. As. 2002, p. 32, 35, 40.
} 
Walter Eduardo Campos Murillo - Aplicabilidad de la teoría de las cargas probatorias dinámicas al Proceso Civil Peruano. Apuntes iniciales

De este modo, se distribuye el riesgo de la falta de prueba de un hecho afirmado, siendo que la consecuencia de dicha falta de prueba recaerá en aquella parte que tenía la carga de aportarla y no lo hizo.

La carga de la prueba encuentra sentido pleno en un proceso sujeto, al menos en sus caracteres esenciales, al principio dispositivo en materia probatoria, es aquí donde encuentra fundamento la distribución de la carga de la prueba, pues siendo las partes las que deben determinar, tanto en la demanda cuanto en la contestación, los hechos que estimen relevantes para que se les reconozca o rechace la pretensión, corresponde a éstas aportar la prueba correspondiente $\mathrm{y}$, consiguientemente, asumir el riesgo de la falta de prueba.

La carga de la prueba, en tanto noción compleja posee un aspecto subjetivo y concreto y, además, otro aspecto objetivo y abstracto. El aspecto subjetivo refiere a que contiene una norma de conducta para las partes, señalándoles que quién afirma debe probar para de ese modo evitar una decisión contraria a sus intereses. Lo concreto se evidencia en que determina, en cada caso específico, los hechos particulares que en cada proceso interesa demostrar a cada parte.

Por su parte, el aspecto objetivo implica una regla de juicio, conforme a la cual cuando falta la prueba de los hechos que fundamentan el litigio, el juez debe proferir una sentencia de fondo desfavorable para quien tenía la carga de suministrar la prueba y no lo hizo, evitándose de este modo el non liquet ${ }^{4}$, es decir la emisión de una sentencia inhibitoria o absolutoria de la instancia por falta de pruebas, de suerte que debe decidirse sobre el fondo aun cuando no haya certeza sobre los hechos del proceso. Lo abstracto se manifiesta en el hecho de que la regla de juicio se haya establecida de manera general y no referida a casos particulares.

\section{LA TEORÍA DE LAS CARGAS PROBATORIAS DINAMICAS ${ }^{5}$}

Para aproximarnos de la manera más fiel posible a los postulados de esta teoría, consideramos pertinente seguir lo dicho al respecto por la doctrina argentina, lugar donde esta teoría se estructura a partir de los escritos del maestro rosarino Jorge PEYRANO.

\footnotetext{
4 Significa: "Me abstengo porque no lo veo claro". Es una fórmula utilizada por los jueces medievales para expresar que no encontraban la solución al asunto que se les planteaba. Como es sabido, las legislaciones modernas adoptan la regla contraria, por la cual los tribunales nunca pueden dejar de sentenciar, debiendo emplear métodos de interpretación en caso de oscuridad o de laguna, tales como la integración y la analogía.

5 Los párrafos que siguen conforme a la siguiente fuente: LUIS VARGAS, Abraham. «Cargas probatorias dinámicas. Sus perfiles actuales y algunas respuestas a sus críticos». Disponible en Internet: http://www. acaderc.org.ar/doctrina/articulos/cargas-probatorias-dinamicas
} 
Walter Eduardo Campos Murillo - Aplicabilidad de la teoría de las cargas probatorias dinámicas al Proceso Civil Peruano. Apuntes iniciales

\section{CONCEPTO.-}

Un concepto cabal sobre la teoría de la cargas probatorias dinámicas, se desprende de lo declarado en un reconocido encuentro de derecho procesal realizado en el vecino país de Argentina; se trata del XVII Congreso Nacional de Derecho Procesal celebrado en la ciudad de Termas de Río Hondo (Santiago del Estero, Provincia de Argentina, situada en la Región del Norte Grande) durante los días 19 al 22 de mayo de 1993 donde se declaró lo siguiente: "1.La temática del desplazamiento de la carga de la prueba reconoce hoy como capítulo más actual y susceptible de consecuencias prácticas a la denominada doctrina de las cargas probatorias dinámicas, también conocida como principio de solidaridad o de efectiva colaboración de las partes con el órgano jurisdiccional en el acopio del material de convicción. 2.- Constituye doctrina ya recibida la de las cargas probatorias dinámicas. La misma importa un apartamiento excepcional de las normas legales sobre la distribución de la carga de la prueba, a la que resulta procedente recurrir sólo cuando la aplicación de aquélla arroja consecuencias manifiestamente disvaliosas. Dicho apartamiento se traduce en nuevas reglas de reparto de la imposición probatoria ceñida a las circunstancias del caso y renuentes a enfoques apriorísticos (tipo de hecho a probar, rol de actor o demandado, etc.). Entre las referidas nuevas reglas se destaca aquélla consistente en hacer recaer el onus probandi sobre la parte que está en mejores condiciones profesionales, técnicas o fácticas para producir la prueba respectiva. Se debe ser especialmente cuidadoso y estricto a la hora de valorar la prueba allegada por la parte que se encuentre en mejor situación para producirla porque, normalmente, la misma también está en condiciones de desvirtuarla o desnaturalizarla en su propio beneficio. 3.- Se recomienda la regulación legal del ideario ínsito en la doctrina de las cargas probatorias dinámicas. Resultaría, en cambio, inconveniente su incorporación legislativa a través de disposiciones taxativas, demasiado casuísticas y que pueden interpretarse de manera flexible, dificultándose así el necesario ajuste de la decisión respectiva a las circunstancias del caso. 4.- Se estima que la invocación judicial oficiosa al momento de sentenciar de la doctrina de las cargas probatorias dinámicas o de concepciones afines, puede prima facie entrañar algún riesgo para la garantía de defensa en juicio. Empero, tal aplicación quedaría cohonestada por constituir aquélla un corolario de las reglas de la sana crítica en materia de valoración de la prueba; preceptos que pueden y deben merituar los tribunales. Además, contribuye en el mismo sentido la normativa legal que consagra la posibilidad de apreciar la conducta procesal de las partes. Igualmente, la audiencia preliminar (oportunidad en que se advertirá a ambas partes sobre los especiales esfuerzos probatorios que deberán encarar), eliminaría el riesgo indicado. De todos modos, se insiste en la necesidad de formalizar, en cualquier supuesto, una prudente y meditada utilización de la susodicha doctrina". 
Walter Eduardo Campos Murillo - Aplicabilidad de la teoría de las cargas probatorias dinámicas al Proceso Civil Peruano. Apuntes iniciales

\section{CARACTERES.-}

Como caracteres que identifican a la teoría de las cargas probatorias dinámicas se reconocen, principalmente, los siguientes:

a) Configuran una especie dentro del género "desplazamiento de las cargas probatorias" (que, por supuesto, incluye otras conocidas figuras, tales como presunciones legales, presunciones hominis, inversión legal o jurisprudencial del onus probandi, reducción de los estándares o módulos de prueba, etc.)

b) Reconocen la vigencia de las normas generales clásicas (rígidas) sobre distribución del onus probandi como "principio general" y, expresamente, asumen que solo corresponde acudir a ellas de manera "excepcional" frente a la situación en que la aplicación de aquellas normas legales (típicas o rígidas) sobre la distribución de la carga de la prueba, arroja consecuencias manifiestamente disvaliosas.

c) En el caso excepcional en que se estime su aplicación, importan un desplazamiento del onus probandi conforme a las especiales circunstancias del caso.

d) El elenco de las mismas es amplio y variado, siendo la más difundida y usada aquella consistente en hacer recaer el onus probandi sobre la parte que está en mejores condiciones profesionales, técnicas o fácticas para producir la prueba respectiva.

e) Modernamente, justifican la adjudicación dinámica aludida, la mayor facilidad probatoria y la disponibilidad de los medios probatorios en que se encuentre la parte a la que originariamente $-\mathrm{y}$ según las reglas típicas, rígidas o legales-, no le correspondía la carga subjetiva de la prueba.

f) Esta teoría ha encontrado aplicación en diversas ramas del derecho.

\section{CONTENIDO.-}

La teoría de las cargas probatorias dinámicas reconoce varias reglas, no existiendo un listado taxativo de las mismas, siendo que toda aquella regla que se justifique en la dificultad probatoria de una de las partes para producir una prueba que beneficie a su interés y, en la facilidad probatoria de la otra para aportar la misma al proceso puede ser incluida en el grupo de estas reglas. 
Walter Eduardo Campos Murillo - Aplicabilidad de la teoría de las cargas probatorias dinámicas al Proceso Civil Peruano. Apuntes iniciales

En efecto, señala Peyrano que: “'Mayor facilidad probatoria' y 'disponibilidad de los medios probatorios' son, pues y a nuestro entender, las razones de ser últimas que fundamentan el grueso de las soluciones vigentes que dominan la distribución del onus probandi (...) Sucede que en la actualidad, novedades legislativas y doctrinarias han sacado del cono de sombras donde se encontraba al concepto de "mayor facilidad probatoria", transformándolo -eso sí, de manera excepcional- en una nueva pauta distributiva del onus probandi. El fenómeno es interesante y elogiable porque flexibiliza la rigidez que estaba dominando el sector de la valoración de la prueba, aportando una visión más ceñida a las circunstancias del caso. Pero dicha aparición no puede hacer perder de vista que resulta inconveniente edificar una construcción tan delicada como la distribución del onus probandi sobre conceptos un tanto subjetivos y con una abundante dosis de discrecionalidad. Los aceptamos como válvula de escape del sistema, y así lo han regulado las legislaciones locales $(. . .)^{\prime \prime}$.

En tal sentido, la regla más conocida de todas es aquella que señala que corresponde hacer recaer el onus probandi sobre la parte que está en mejores condiciones profesionales, técnicas o fácticas para producir la prueba respectiva.

\section{APLICACIÓN DE LA TEORÍA DE LAS CARGAS PROBATORIAS DINÁMICAS EN EL ÁMBITO NACIONAL_}

Esta teoría, pese a no haber sido recogida legislativamente en sede nacional, ha encontrado aplicación práctica en diversos ámbitos del derecho, así podemos identificar, a guisa de ejemplo, los siguientes casos:

\section{1) Ámbito Constitucional.-}

El supremo intérprete de la Constitución ha desarrollado lo relativo a las cargas probatorias dinámicas en más de una oportunidad:

a) En el proceso de amparo seguido por don Víctor Augusto Morales Medina, expediente número 1176- 2004-AA/TC, en el que el demandante solicita que se deje sin efecto el contrato de afiliación que suscribió con la AFP Unión Vida para su inscripción al Sistema Privado de Pensiones $\mathrm{y}$, consiguientemente, su traspaso al Sistema Nacional de Pensiones, el

6 PEYRANO, Jorge W. «Carga de la Prueba: Las razones de ser que explican el reparto de esfuerzos probatorios: la mayor facilidad probatoria y la disponibilidad de los medios probatorios»; exposición en las Segundas Jornadas de Profesores orientada al análisis crítico y al debate en Homenaje al Prof. Oscar Martínez, La Plata 29 y 30 de septiembre de 2006. 
Walter Eduardo Campos Murillo - Aplicabilidad de la teoría de las cargas probatorias dinámicas al Proceso Civil Peruano. Apuntes iniciales

Tribunal Constitucional señaló en el numeral " $\mathrm{c}$ " del fundamento jurídico número 50, que:

"Pese a lo claro que puede resultar el procedimiento regular que debe realizarse con posterioridad a que una demanda sea declarada fundada, este Colegiado considera propicio este punto a fin de explicar algunas cuestiones que pueden resultar controversiales. (...) c. La utilización de la prueba dinámica. Se ha señalado prima facie que la carga de probar corresponde a quien afirma hechos que configuran su pretensión, o a quien los contradice alegando nuevos hechos, según lo presenta el artículo $196^{\circ}$ del Código Procesal Civil. Frente a ello, $\underline{\text { la }}$ carga probatoria dinámica significa un apartamiento de los cánones regulares de la distribución de la carga de la prueba cuando ésta arroja consecuencias manifiestamente disvaliosas para el propósito del proceso o procedimiento, por lo que es necesario plantear nuevas reglas de reparto de la imposición probatoria, haciendo recaer el onus probandi sobre la parte que está en mejores condiciones profesionales, técnicas o fácticas para producir la prueba respectiva. En el caso de la falta de información para una afiliación, este precepto no puede ser adecuado, pues reparándose en la naturaleza de los hechos a probar, se puede llegar a pensar en la remisión a un subjetivismo de la SBS, tal como lo reconocía casi explícitamente la nulidad de afiliaciones. Conviene ahora desvirtuar la validez de la 'prueba diabólica' que puede llegar a ser la probanza de que el afiliado no fue informado de forma conveniente. Un medio probatorio produce certeza en el juez respecto de los puntos controvertidos con el fin de fundamentar sus decisiones. Y sobre ello hay que insistir en el caso del retorno al SNP por falta de información correcta sobre el SPP y sobre el futuro del SNP, máxime si tal figura se justifica precisamente con la asimetría informativa y con la firma de un contrato de adhesión. La doctrina de las cargas probatorias dinámicas interviene para responder a una concepción de un derecho dúctil y una concepción más dinámica del devenir del proceso, tal como amerita el supuesto planteado. Así, no correspondería al demandante la carga de la prueba del hecho (de indole negativo) sino que el demandado tendría la carga de probar el hecho positivo. Cabe recordar que la prueba dinámica no es ajena a nuestro ordenamiento. Por ejemplo, se han utilizado en los siguientes supuestos: violación de derechos humanos (párrafo 70 de la sentencia del caso Paniagua Morales y otros, párrafo 65 de la sentencia del caso Durand y Ugarte y párrafo 63 de la sentencia del Caso Castillo Petruzzi, todas ellas de la Corte Interamericana de Derechos Humanos), cumplimiento de condiciones de los trabajadores (artículo $27^{\circ}$ de la Ley Procesal del Trabajo, Ley N. ${ }^{\circ}$ 26636) e impugnación de pago de tasa en tributación municipal (sentencias recaídas en el Expediente N. $.^{\circ} 0041-2004-A I / T C$ y en el Expediente 0053-2004-AI/ 
Walter Eduardo Campos Murillo - Aplicabilidad de la teoría de las cargas probatorias dinámicas al Proceso Civil Peruano. Apuntes iniciales

TC). Asimismo, en el ámbito de protección del usuario, y basándose en la asimetría de información, se ha permitido la variación de la carga de la prueba, buscándose proteger al consumidor de la imposibilidad de probar que fue engañado o que recibió información insuficiente (punto 2 la Resolución $N^{o}$ 102-97-TDC-INDECOPI)". (resaltado nuestro)

b) De manera similar, en el proceso de inconstitucionalidad correspondiente al expediente número 0041-2004-AI/TC, caso seguido. por la Defensoría del Pueblo contra diversas Ordenanzas expedidas por la Municipalidad de Santiago de Surco, que aprobaron el régimen legal tributario y los importes de los arbitrios municipales para el ejercicio fiscal 2004, señaló en el fundamento jurídico número 61 que:

"La evaluación de la confiscatoriedad cuantitativa tiene una mayor dificultad por cuanto debe determinarse, primero, si el costo global del servicio es el que verdaderamente corresponde al gasto incurrido por el Municipio; $y$, luego, si la distribución de dichos costos entre la totalidad de contribuyentes, ha sido tal, que cada contribuyente termine pagando lo que verdaderamente le corresponde por el beneficio, en función a la intensidad del uso del servicio. Es en este último caso donde radica la mayor dificultad para determinar lo que verdaderamente corresponde pagar y cuál sería el exceso, sobre todo cuando se habla en términos de beneficio potencial. Por ello, es más coherente que, en caso de conflicto, la carga de la prueba respecto a la efectiva prestación del servicio, le corresponda a la administración municipal" (resaltado nuestro).

c) Asimismo, en otro proceso de inconstitucionalidad, referido al expediente 000532004-PI/TC, caso seguido también por la Defensoría del Pueblo contra diversas Ordenanzas emitidas por la Municipalidad Distrital de Miraflores, también sobre temas de tributación municipal, el Tribunal Constitucional ha señalado que:

"Si bien el contribuyente que discrepa sobre la carga económica asumida por arbitrios debe adjuntar en su reclamo administrativo o posterior acción judicial los elementos mínimos que certifiquen lo que alega (liquidaciones, órdenes de pago, determinaciones y otros elementos que demuestren la falta de recursos para asumir la carga tributaria o la falta de disposición del servicio cobrado), conforme se señaló en el fundamento 61 de la STC N. ${ }^{\circ}$ 0041-2004-AI/TC, debido a la complejidad técnica que supone demostrar lo que verdaderamente corresponde pagar de manera individualizada a cada contribuyente y el posible exceso en el cobro, el Tribunal considera que, en última 
Walter Eduardo Campos Murillo - Aplicabilidad de la teoría de las cargas probatorias dinámicas al Proceso Civil Peruano. Apuntes iniciales

instancia, la carga de la prueba en estos casos debe invertirse y recaer en la municipalidad, pues esta se encuentra en mejores condiciones técnicas para asumirla". (resaltado nuestro)

\section{2) ÁMBito DE PROTECCIÓN AL CONSUMIDOR.-}

El Tribunal de Defensa de la Competencia y la Propiedad Intelectual INDECOPI- también ha tenido oportunidad de aplicar la TCPD, ello se evidencia en el caso de doña Liliana Carbonel Cavero, tramitado ante dicha entidad con el expediente $\mathrm{N}^{\circ}$ 327-96-C.P.C. en la denuncia que interpone ésta contra la agencia de viajes Finantour S.R.L., por infracción a la Ley de Protección al Consumidor; en esta oportunidad, el Tribunal competente del INDECOPI, a través de la Resolución N ${ }^{\circ}$ 102-97-TDC en el punto III.2, ha señalado que:

"Siendo que de los documentos que obran en el expediente y de las actuaciones realizadas no es posible determinar si se informó o no el número de escalas que haría el vuelo que transportó a la denunciante y a sus menores hijas, la discusión se centra en torno a si el número de escalas era el que normalmente podría esperar un consumidor razonable dadas las circunstancias. De considerarse que ello no es así y que, por tanto, habrían más escalas de las previsibles, podrá considerarse que la denunciada incumplió su obligación de informar adecuadamente al consumidor. La denunciada ha expresado que: "Nunca se me dijo en Lima que el itinerario del avión era otro: Lima - Panamá - Costa Rica - México - Los Angeles; un vuelo demasiado largo y que resultó tremendamente perjudicial para mis dos menores hijas...". No existen pruebas fehacientes respecto a si se le informó o no a la denunciante acerca de las escalas del vuelo contratado, existiendo unicamente el dicho de las partes: la denunciante expresa que no se le informó y la denunciada, por el contrario, que sí cumplió con informarle al respecto. La Sala es de la opinión que, un consumidor en los términos antes señalados, podría prever que en un vuelo de Lima a Los Angeles exista una o hasta dos escalas, en función de la información que le proporciona el mercado, ya sea por su propia experiencia o por la de terceras personas. En tal sentido, atendiendo a lo expresado anteriormente, la carga de la prueba sobre si se informó o no al consumidor respecto de la existencia de escalas que no eran previsibles empleando su diligencia ordinaria debe ser asumida por aquél que maneja esta información y se encuentra en mejor posición para producir prueba sobre tal hecho: el proveedor es quien se encuentra en mejor posición para poder demostrar si efectivamente informó al consumidor sobre estas circunstancias no previsibles. En el presente caso, sin embargo, la denunciada no ha presentado prueba alguna que demuestre que informó al consumidor del número de escalas existentes. Por los motivos 
Walter Eduardo Campos Murillo - Aplicabilidad de la teoría de las cargas probatorias dinámicas al Proceso Civil Peruano. Apuntes iniciales

expuestos, la Sala considera que debe confirmarse la resolución impugnada en este extremo por haberse vulnerado el derecho del consumidor a recibir la información adecuada previsto en los artículos 5 inciso b) y 15 del Decreto Legislativo $N^{\circ} 716^{\prime \prime}$. (resaltado nuestro)

\section{3) Ámbito JURISDicCIONAL.-}

El Poder Judicial también ha acudido al auxilio de la TCPD para resolver algunos casos, entre ellos podemos mencionar los siguientes ${ }^{7}$ :

a) En la casación número 1385-2004-Lima, publicada en el Diario Oficial El Peruano con fecha 31 de mayo del 2005, referido a un proceso de nulidad de acto jurídico por la causal de simulación absoluta ha señalado que:

"El colegiado ha desestimado pues las máximas de la experiencia no demuestran el acto simulado, obviando que la doctrina refiere, como en el expediente 487198 del 21 de junio de 1999, que la simulación absoluta se configura cuando se aparenta celebrar un acto jurídico y no existe realmente voluntad de hacerlo, lo que la de vista no desarrolla ni analiza, dejándolo al mero criterio de la probanza de enlace y máxima; y para el segundo cargo aduce que el Colegiado obvia la jurisprudencia aportada, donde en los casos de simulación debe de aplicarse la carga probatoria dinámica conforme a la causa 4217-98 (...)". (resaltado nuestro)

b) En similar sentido, en una sentencia emitida el 20 de mayo de 1999 por la, en aquel entonces, Sala de Procesos Abreviados y De Conocimiento de la Corte Superior de Justicia de Lima, en el expediente 4116-98, también en un proceso de nulidad de acto jurídico por simulación, ha dejado establecido en su quinto considerando lo siguiente:

"La controversia no debe resolverse bajo el esquema que al actor le incumbe probar los hechos constitutivos y al demandado acreditar los hechos modificativos, impeditivos y extintivos invocados en su propio mecanismo; sino que en materia de simulación, la doctrina reconoce la llamada carga probatoria dinámica, la que se encuentra referida a situaciones jurídicas, esto es, situaciones de expectativa, esperanza de la conducta jurídica que ha de producirse, según la cual, la carga probatoria se traslada a quien se encuentra en mejores condiciones para producirla" (resaltado nuestro).

7 Citados por: HuRTADO REYES, Martín. «Fundamentos del derecho procesal civil». Lima: IDEMSA, 2009, p. 592. 
Walter Eduardo Campos Murillo - Aplicabilidad de la teoría de las cargas probatorias dinámicas al Proceso Civil Peruano. Apuntes iniciales

\section{V. ¿ES NECESARIA SU REGULACIÓN NORMATIVA EXPRESA EN EL CÓDIGO PROCESAL CIVIL?}

Si bien es posible convenir en que el Código Procesal Civil contiene una norma afín a las ideas que sustentan la TCPD, esto es la norma prevista en el artículo $282^{8}$, debe considerarse que la facultad ahí establecida no parece habilitar al Juez a fallar estableciendo criterios distributivos de la carga probatoria distintos e incluso contrarios a la regla establecida en el artículo 196 del mismo código, que contiene el principio general de distribución del onus probandi, pues el evaluar la mala conducta de alguna de las partes permite, en todo caso, que el Juez establezca indicios probatorios en contra de tal litigante, pero de modo alguno le permite exonerar a una de las partes de la carga de probar, desde que ello implicaría invertir la carga de la prueba en contra de lo previsto expresamente en nuestro ordenamiento procesal.

De otro lado, una de las principales críticas que se han exhibido contra la TCPD es que afecta el derecho de defensa en juicio, pues si el juez cambia las reglas de juego a última hora, esto es al momento de expedir su fallo, sin previo conocimiento de las partes, perjudica el derecho de defensa de éstas y, con ello, afecta uno de los contenidos esenciales del debido proceso, lo que en definitiva resulta inconstitucional. Así, se dice que en los supuestos de aplicación de la TCPD, la parte no sabe de antemano cuáles son los hechos que le corresponde probar, pues eso lo dirá el Juez cuando dicte sentencia, es decir cuando ya no pueda probar. En esta línea, es pertinente citar al profesor Alvarado Velloso cuando señala que: "En otras palabras y recurrentemente: cambiar las reglas del juego después que el juego terminó, convirtiendo en ganador al claro perdedor según las normas tenidas en cuenta por los jugadores durante todo el desarrollo del certamen, no sólo es actitud desleal sino que, en el proceso, viola la garantía de la defensa en juicio. ¡Por mucho empeño justiciero que ostente el Juez actuante!" (sic) ${ }^{9}$.

A nuestro entender, la aplicación de la TCPD, aunque de manera excepcional, permite restarle algo de rigidez a la regla general del reparto de la carga probatoria a fin de acercarse a la justicia en el caso concreto; de ahí la

\footnotetext{
8 TEXTO ÚNICO ORDENADO DEL CÓDIGO PROCESAL CIVIL. RESOLUCIÓN MINISTERIAL No 010-93JUS

Artículo 282.- Presunción y conducta procesal de las partes.-

El Juez puede extraer conclusiones en contra de los intereses de las partes atendiendo a la conducta que éstas asumen en el proceso, particularmente cuando se manifiesta notoriamente en la falta de cooperación para lograr la finalidad de los medios probatorios, o con otras actitudes de obstrucción. Las conclusiones del Juez estarán debidamente fundamentadas.

9 Alvarado Velloso, Adolfo. «El debido proceso de la Garantía Constitucional». Rosario: Editorial Zeus SRL., 2003, p. 199.
} 
Walter Eduardo Campos Murillo - Aplicabilidad de la teoría de las cargas probatorias dinámicas al Proceso Civil Peruano. Apuntes iniciales

necesidad de su adopción, particularmente en aquellos casos en que la parte que debe aportar la prueba no obtenga tutela jurisdiccional efectiva pues la disponibilidad o facilidad del medio probatorio está en manos de la contraparte, casos tales como cuando es indispensable acceder a una muestra de la contraparte para poder analizar su ADN, o a sus registros contables, o los pagarés firmados en blanco que mantiene una entidad bancaria, o del servidor del demandado para determinar si fue quien envió los correos electrónicos, o en los casos de responsabilidad por mala praxis médica, o en los supuestos de nulidad del acto jurídico por simulación, etc.; sin embargo, no resulta conveniente que su aplicación se sustente en consideraciones judiciales aisladas que pueden terminar siendo arbitrarias o, en versiones doctrinarias que, en tanto contradicen al marco normativo procesal civil vigente, generan incertidumbre.

En tal sentido, admitida su conveniencia, estimamos que es pertinente que se regule normativamente de manera expresa, de suerte que, de un lado se le conceda al Juez una herramienta que le permita flexibilizar la carga de la prueba, de manera excepcional, en aquellos casos en que aparezca evidente en que una de las partes tiene el control sobre la prueba o que el acceso a la misma para la otra parte deviene en muy difícil o excesivamente onerosa y, de otro lado, se les brinde a los litigantes un marco normativo que asegure debidamente su derecho de defensa y la seguridad jurídica, posibilitando de este modo la aplicación de la TCPD en concordancia con las normas constitucionales que preservan el debido proceso, particularmente, el derecho de defensa en juicio.

\section{PROPUESTA NORMATIVA}

La adopción de la TCPD, importa la necesidad de modificar el artículo 196 del Código Procesal Civil, por lo que en una lógica de lege ferenda, nos permitimos sugerir el siguiente texto normativo:

\section{Artículo 196.- Carga de la prueba.-}

Salvo disposición legal diferente, la carga de probar corresponde a quien afirma hechos que configuran su pretensión, o a quien los contradice alegando nuevos hechos. Sin embargo, si las circunstancias especiales del caso lo justifican, el Juez, en resolución debidamente motivada, puede distribuir la carga de la prueba, ponderando cuál de las partes está en mejor situación para aportarla. Esta resolución debe dictarse con anterioridad a lo dispuesto en el artículo 211 y notificarse a las partes para que en el plazo de cinco días ofrezcan las probanzas pertinentes. 
Walter Eduardo Campos Murillo - Aplicabilidad de la teoría de las cargas probatorias dinámicas al Proceso Civil Peruano. Apuntes iniciales

\section{REFLEXIONES FINALES}

La existencia de diversos supuestos en los que la posibilidad de que la parte que tiene la carga de la prueba se vea imposibilitada de producir los medios de prueba necesarios a su interés porque las fuentes de prueba se encuentran en manos de la parte contraria, evidencian la conveniencia de la utilización, aunque limitada a estos casos excepcionales, de la TCPD. No obstante, a fin de que la misma sea aplicaba de manera tal que asegure la seguridad jurídica y no se convierta en una herramienta que termine afectando el derecho de defensa en juicio de las partes, es necesario que sea regulada de manera expresa en la norma procesal, aunque, relevando su carácter excepcional y, a través de una fórmula que lejos de ser taxativa, brinde al Juez un margen de actuación que pueda ser adecuada a cada caso concreto. En este sentido es que en el presente trabajo nos permitimos aportar un proyecto de texto normativo. 